Document downloaded from:

http://hdl.handle.net/10251/36562

This paper must be cited as:

Vercher Sanchis, JM.; Lerma Elvira, C.; Vidal Martinez, M.; Gil Benso, E. (2013). Analysis of Energy Efficiency in Construction Solutions at the Facade-slab Connection. Advanced Materials Research. 787:731-735. doi:10.4028/www.scientific.net/AMR.787.731.

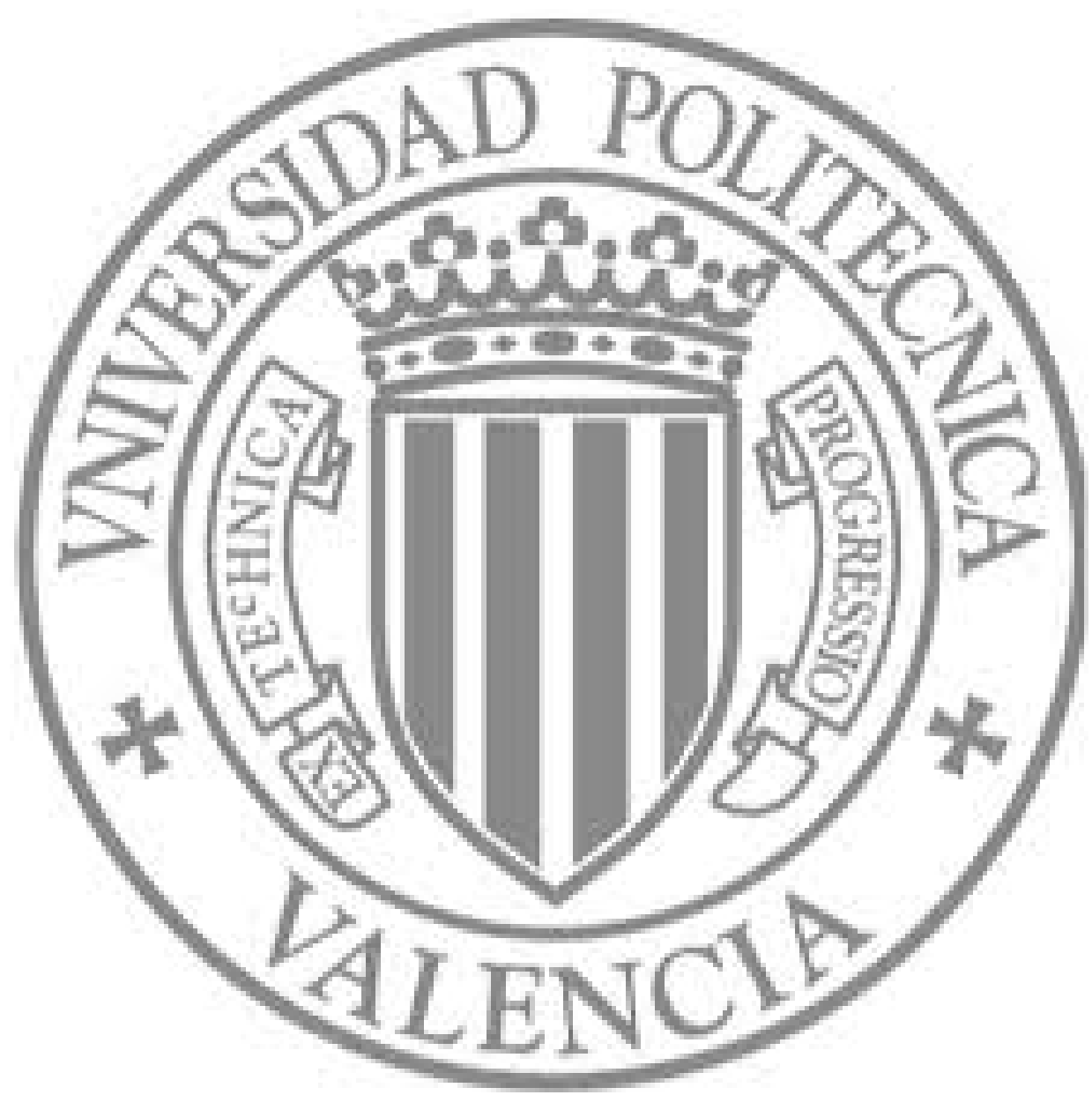

The final publication is available at

http://dx.doi.org/10.4028/www.scientific.net/AMR.787.731

Copyright Trans Tech Publications 


\title{
Analysis of energy efficiency in construction solutions at the façade-slab connection
}

\author{
Jose VERCHER ${ }^{1, a}$, Carlos LERMA ${ }^{1, b}$, Marisol VIDAL ${ }^{2, c}$ and Enrique GIL ${ }^{1, d}$ \\ ${ }^{1}$ Universitat Politècnica de València. Cmno. De Vera s/n 46022 Valencia (Spain) \\ ${ }^{2}$ Graz University of Technology, Graz (Austria) \\ ajvercher@csa.upv.es, ${ }^{b}$ clerma@csa.upv.es, ${ }^{c}$ marisol.vidal@tugraz.at, ${ }^{d}$ egil@mes.upv.es
}

Keywords: Heat loss, condensation, thermal insulation, thermal bridge

\begin{abstract}
Façade-slab connection is the main thermal bridge of buildings. In this work, different options are analyzed according to the location of the thermal insulation. Heat loss is measured for each option. According to thermal analysis performed we conclude that cover the building's façade completely without interruption at the slab's front is essential to avoid thermal bridges. The new option that interrupts the cantilever to put insulation on the entire façade is just effective to isolate the entire cantilever and is an easier constructive solution. This insulation continuity is needed to prevent ceiling condensation, since the energy saving is not important compared to windows thermal loss.
\end{abstract}

\section{Introduction}

This study covers one of the most interesting areas of buildings from the point of view of energy, and it is the façade-slab connector. Our study raises the most common possibilities depending on the thermal insulation position. Thermal insulation can be placed outside of façade, in an intermediate position or inside.

Also, the possibility of including a cantilever (small balcony is typical) is introduced. The cantilever does not generate any structural problems. Equilibrium of external action arises with loads placed on the reinforcement that cross thermal isolation.

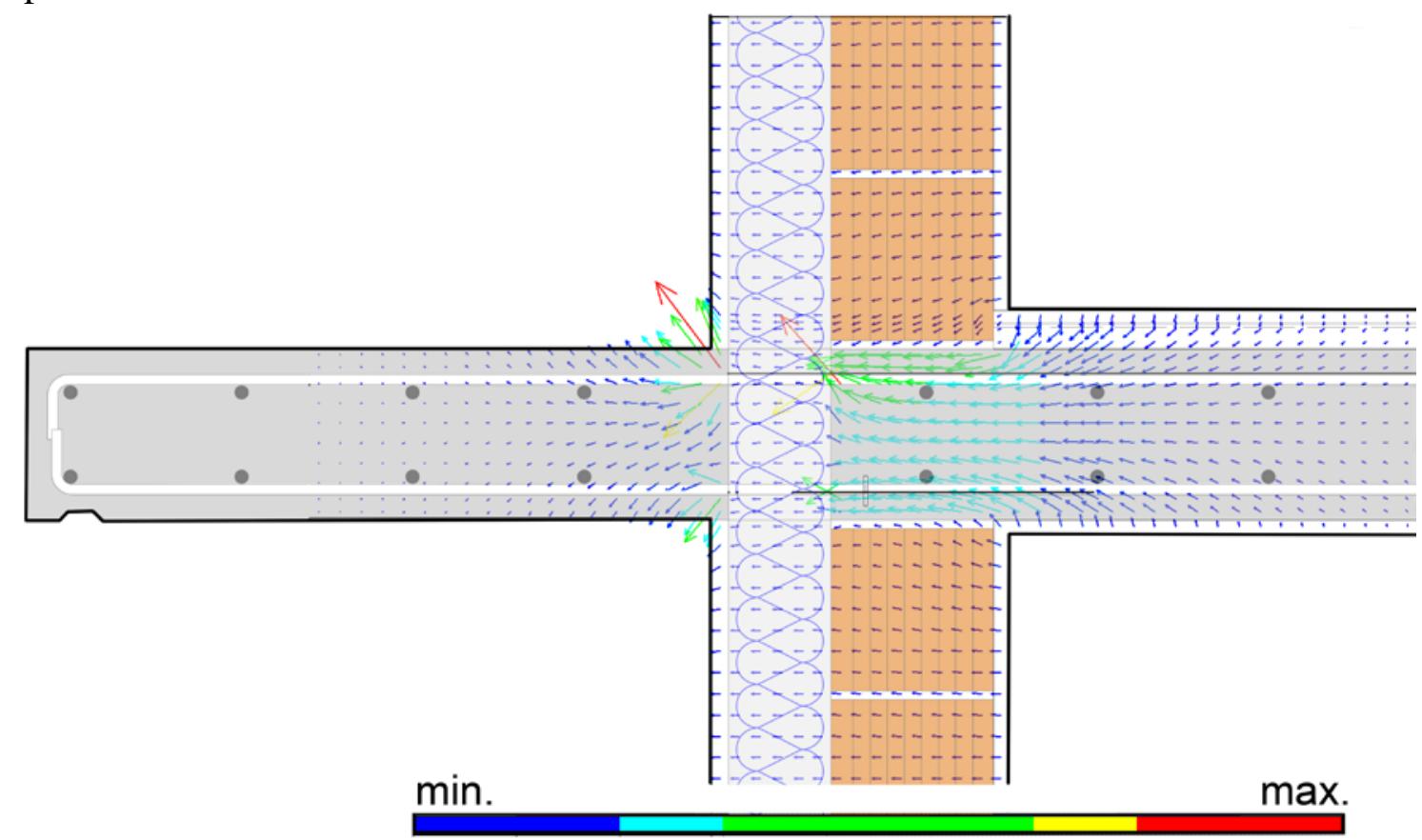

Figure 1: Thermal flow through the façade in each case. 
Fig. 1 shows the outgoing heat flow in a façade with exterior thermal insulation and it interrupts the slab continuity with the cantilever through a prefabricated piece. Outgoing thermal flow focuses on stainless steel bars although they have three times lower conductivity than normal steel.

Our work has focused on a conflict and specific area of the building. For an overall building's thermal analysis can be seen [1]. Selected weather conditions are extreme, with $263{ }^{\circ} \mathrm{K}$ outside $(-10$ $\left.{ }^{\circ} \mathrm{C}\right)$ and $293^{\circ} \mathrm{K}\left(20^{\circ} \mathrm{C}\right)$ inside. Materials and their specific characteristics (density, conductivity and specific heat) can be contrasted in Table 1.

\begin{tabular}{|c|c|c|c|c|c|c|c|}
\hline Material & $\begin{array}{c}\text { Density } \\
\mathrm{Kg} / \mathrm{m}^{3}\end{array}$ & $\begin{array}{c}\text { Conductivity } \\
\mathrm{W} /(\mathrm{m} \cdot \mathrm{K})\end{array}$ & $\begin{array}{c}\text { Specific } \\
\text { heat } \\
\mathrm{J} /(\mathrm{kg} \cdot \mathrm{K})\end{array}$ & Material & $\begin{array}{c}\text { Density } \\
\mathrm{Kg} / \mathrm{m}^{3}\end{array}$ & $\begin{array}{c}\text { Conductivit } \\
\mathrm{y} \\
\mathrm{W} /(\mathrm{m} \cdot \mathrm{K})\end{array}$ & $\begin{array}{c}\text { Specific } \\
\text { heat } \\
\mathrm{J} /(\mathrm{kg} \cdot \mathrm{K})\end{array}$ \\
\hline air & 1.225 & 0.024 & 707 & stone & 2750 & 3.500 & 880 \\
\hline insulate & 80 & 0.040 & 1400 & aluminum & 2700 & 232.0 & 920 \\
\hline glass & 2500 & 0.950 & 836 & concrete & 2400 & 1.630 & 805 \\
\hline plaster & 900 & 0.300 & 920 & steel & 7850 & 52.50 & 460 \\
\hline mortar & 2000 & 1.400 & 1050 & stainless st. & 7850 & 15.0 & 510 \\
\hline
\end{tabular}

Table 1. Materials properties.

\section{Method}

The methodology we have used considers the most common cases of façade-slab connection. Thermal insulation position (outside, inside or intermediate position) has been considered to calculate these three cases. We have also introduced a cantilever to observe what happens, also considering the three positions of the thermal insulation. In the last case, thermal insulation has been incorporated outside including the cantilever.

Simulation was carried out using Ansys finite element with the element type plane Plane 55 and the steel bars by Link 33 .
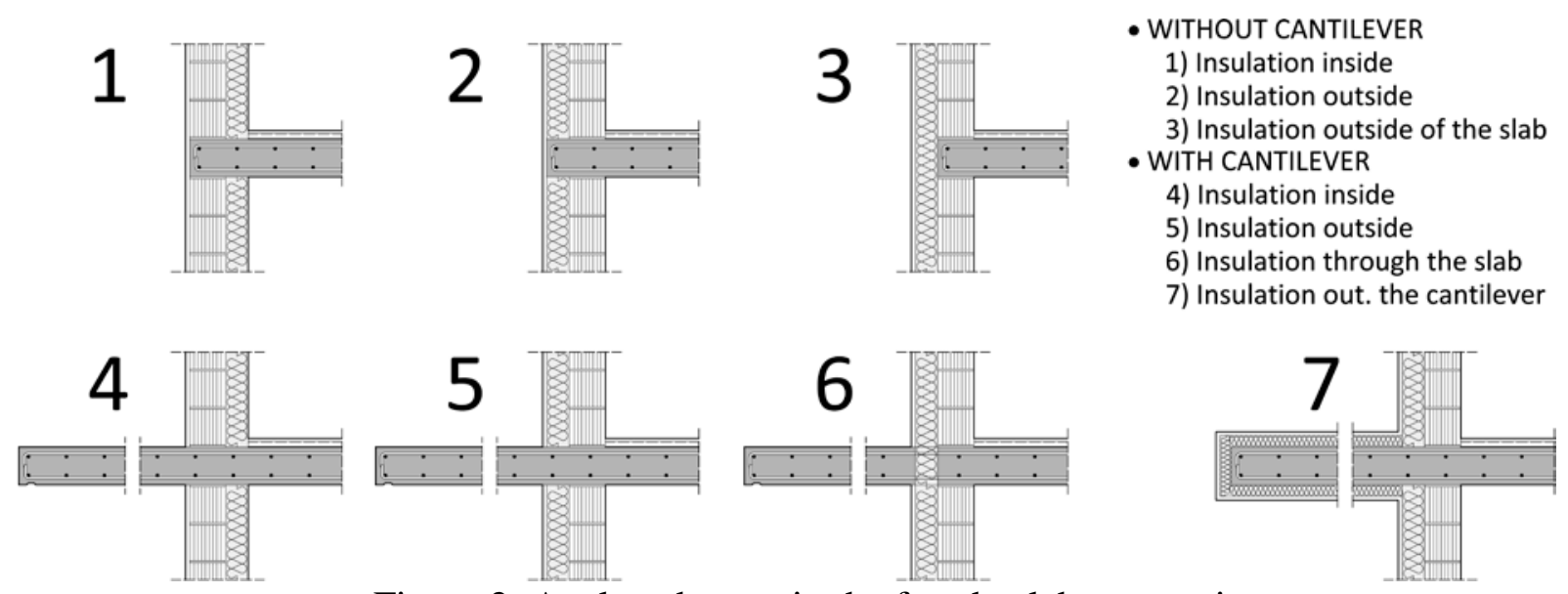

Figure 2: Analyzed cases in the façade-slab connection.

Fig. 2 plotted the constructive section of each analyzed cases. The constructive section consists of a reinforced concrete slab of $20 \mathrm{~cm}$ and a thermo-clay block of $19 \mathrm{~cm}$ thickness on the façade. Thermal insulation used has $12 \mathrm{~cm}$ of thick. Continuous covering is a monolayer mortar of $2 \mathrm{~cm}$ thick. Inside the building a wood floor of $1 \mathrm{~cm}$ has been used on a $3 \mathrm{~cm}$ layer of self-leveling mortar, placing between them a sheet of polyethylene.

In case 1, we located thermal insulation inside of building. In case 2, thermal insulation is located on the outside of the thermo-clay blocks but is interrupted at the slab, and is covered by the monolayer mortar. In case 3, thermal insulation warp the structure. Cases 4, 5, 6 and 7 incorporate a cantilever of $1.4 \mathrm{~m}$, but the façade composition is corresponding to the cases 1,2 and 3 respectively. Case 6 is that thermal insulation is outside of thermo-clay blocks; it is between the slab and the 
cantilever. It is therefore necessary to employ some of the patents to connect the cantilever to the slab and maintain its stability while increasing thermal insulation. For a detailed calculation can be seen [2]. Case 7 raises the option that was used a few years ago that wrapping with insulation the building, even cantilever around.

The effect of the thermal bridge, which occurs through the mortar joints in this type of façade [3], is not considered here because the thermal insulation is situated on the outside or inside, but always interrupts the continuity of heat flow.

The balcony, as an architectural element of a building, has been widely used in a variety of geographical areas, especially in regions with temperate and humid tropical climates. The purpose of the balcony is to offer residents an easy access to the external environment. However, its parapet and flooring have a significant impact on the environmental performance of the building, in terms of factors such as natural ventilation, thermal comfort, pollutant transport and shade and natural lighting [4].

\section{Results}

The effect of the insulation situation is very evident by observing the graphs of Fig. 3, differing where the insulation is located inside or outside. In cases where the insulation is placed on the outside and is not interrupted by the slab, the temperatures are more uniform. The concrete of the cantilever, regardless of the length, has the outside temperature except in case 7 , wherein the cantilever is wrapped with insulation.

The cantilever stability does not generate problems, despite of the cutting that produces the thermal insulation in the concrete section. The continuity of some of the horizontal steel bars is enough to balance the moments of external actions, and adding inclined bars through the insulation effectively collects vertical action.

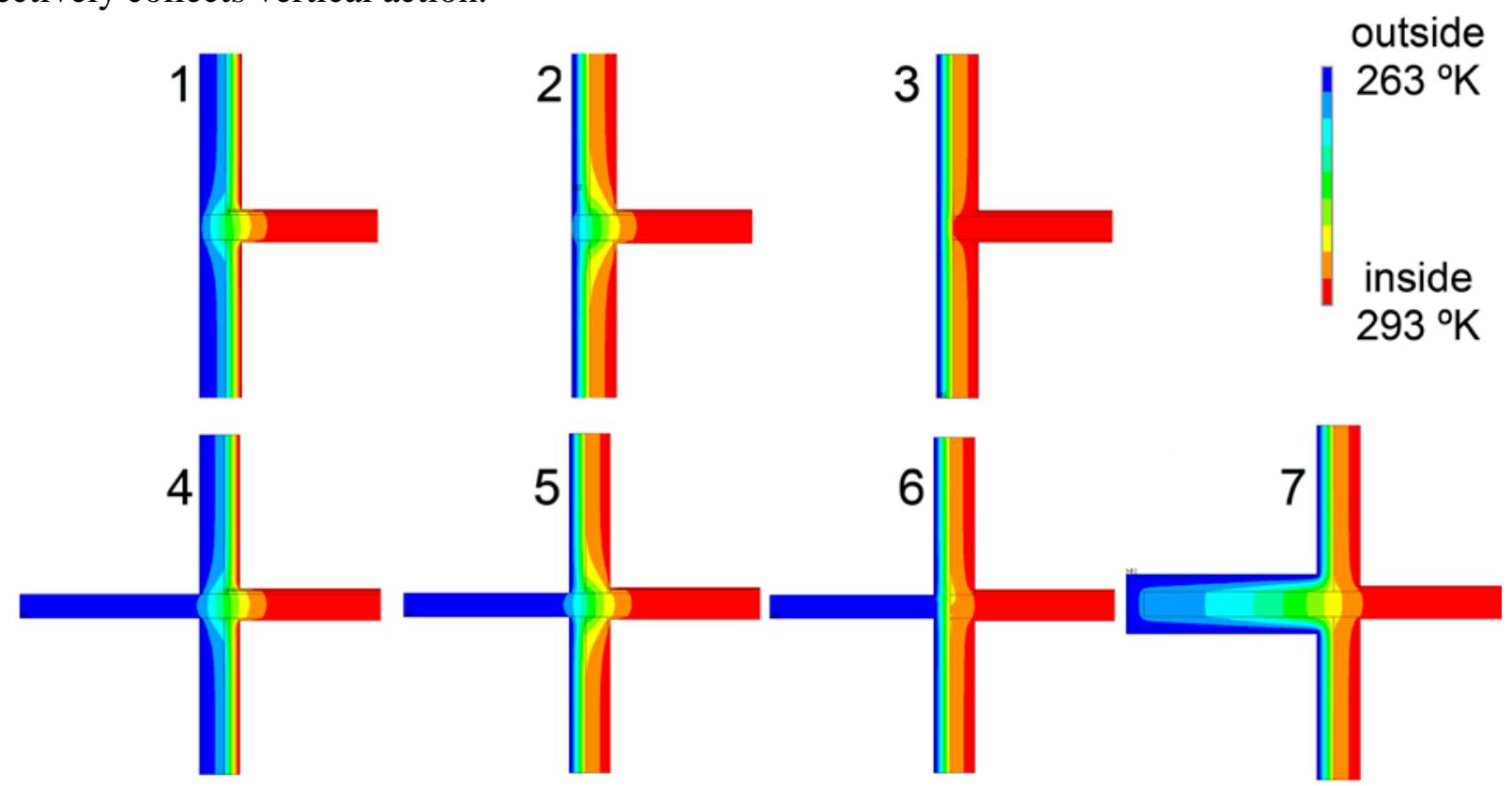

Figure 3: Temperature through the enclosure in each case.

Fig 4 shows the temperature flow by vectors indicating the direction and magnitude of heat loss. The shown values in this figure are relative. For example, in cases 1 and 2, the heat losses are focused in front of the slab. However, in case 3, by providing insulation on the exterior of the slab, the differences along the façade are smaller, being still bigger the losses through the slab. The cases 4 and 5, in the same way as the cases 1 and 2, show the heat loss through the slab (see Table 2). By contrast, in the case 6, which interrupts the concrete cantilever, it can be seen that the steel reinforcement has a high conductivity and losses are concentrated at these points (Fig 1). In case 7 , 
the heat loss is not significant at any point because the cantilever is wrapped with insulation, so that the vectors of greater magnitude indicate the steel bars.

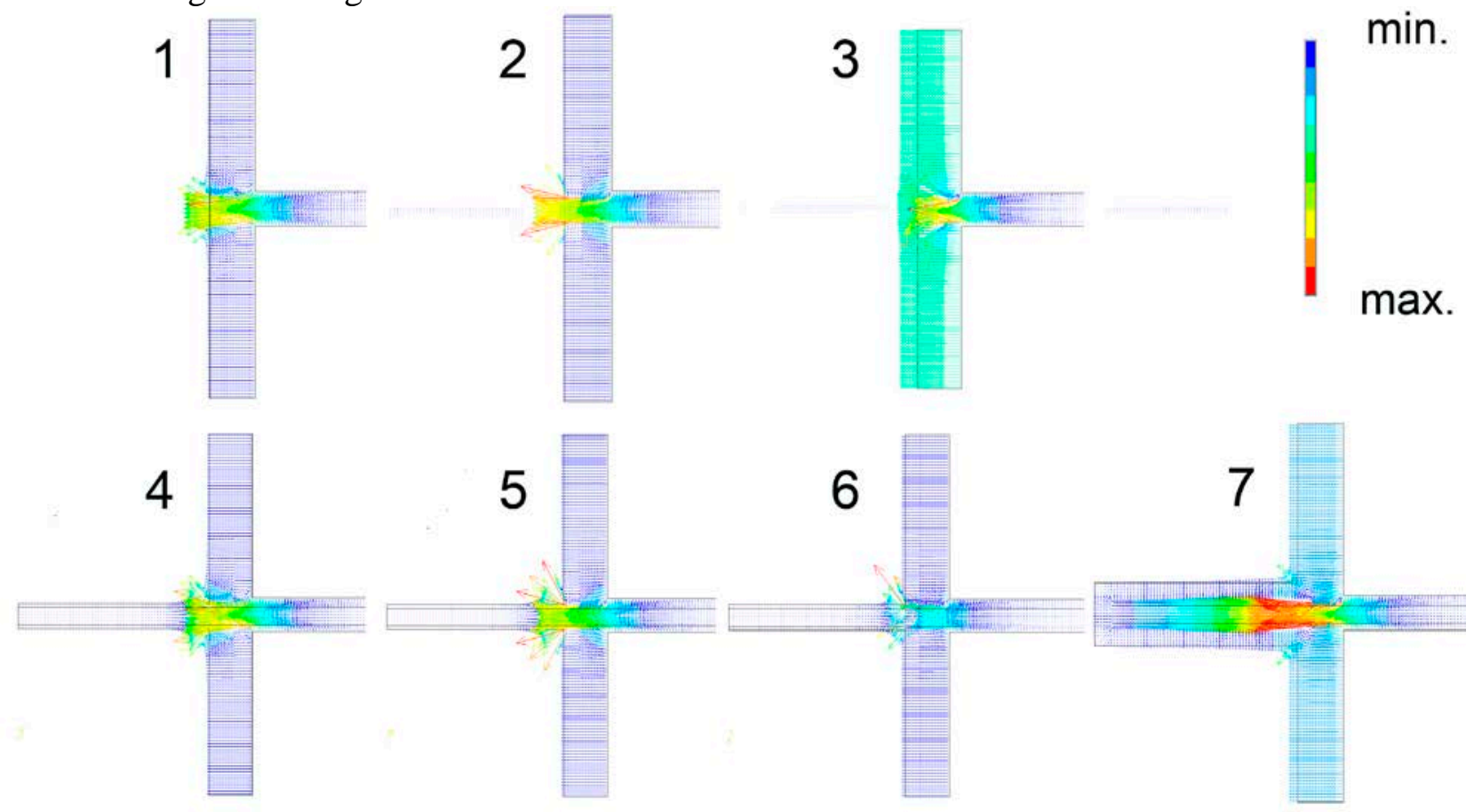

Figure 4: Heat flow through the enclosure in each case.

\begin{tabular}{|c|c|c|c|c|c|c|c|c|}
\hline$\Delta \mathrm{T}=30^{\circ}$ & 1 & 2 & 3 & 4 & 5 & $6 \mathrm{a}$ & $6 \mathrm{~b}$ & 7 \\
\hline $\mathrm{W} / \mathrm{m}$ & 39.671 & 40.501 & 22.538 & 39.731 & 40.504 & 26.388 & 25.478 & 26.326 \\
\hline & $97.94 \%$ & $99,99 \%$ & $55.64 \%$ & $98.09 \%$ & $100 \%$ & $65,15 \%$ & $52.9 \%$ & $65,00 \%$ \\
\hline
\end{tabular}

Tabla 2. Heat flow outward from the façade plane $(\mathrm{W} / \mathrm{m})$.

\begin{tabular}{|c|c|c|c|c|c|c|c|}
\hline$\Delta \mathrm{T}=30^{\circ}$ & 1 & 2 & 3 & 4 & 5 & 6 & 7 \\
\hline $\mathrm{W} / \mathrm{m}$ & 133.67 & 136.25 & 20.74 & 124.70 & 138.17 & 95.74 & 44.10 \\
\hline
\end{tabular}

Tabla 3. Maximum value of heat flow $(\mathrm{W} / \mathrm{m})$.

In table 2 we have summarized the heat flow values for the various analyzed cases. The percentages relative to the higher loss case (case 5) are also shown in order to compare between them. The value of the $6 \mathrm{a}$ case refers to normal steel reinforcement, and $6 \mathrm{~b}$ case refers to stainless steel bars. In Table 3 the maximum values of heat flow are indicated. A fragment of the building with a height corresponding to a room has been modeled, so that the values represented in the tables show the amount of heat lost per linear meter of façade.
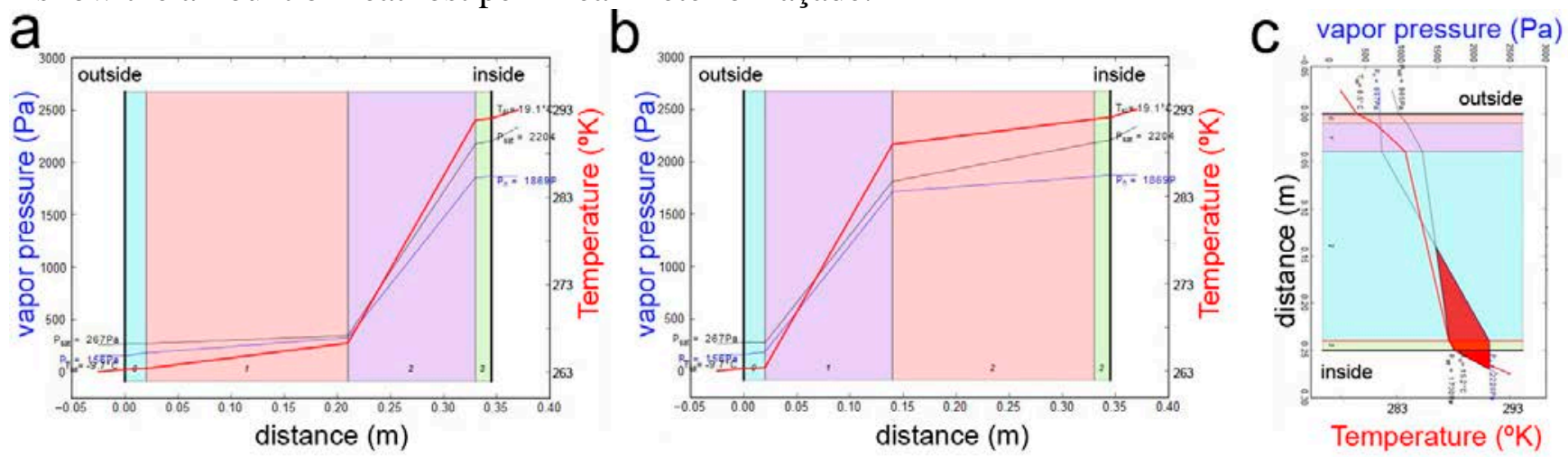

Figure 5: Condensation assessment in the façade and the slab. 
The possible condensation in extreme conditions and the unoccupied flats force to solve the thermal bridge. As shown in Figure 5a and 5b, condensation does not occur in the façade, both with external or internal insulation. Another main point to analyze is the underside of the slab in its encounter with the façade, where in many cases there is condensation. In the extreme case that the upper flat is unoccupied (temperature $281^{\circ} \mathrm{K}$ and $80 \%$ Relative Moisture), the condensation appears (Fig. 5c). Therefore, in case 6 is appropriate to place the lower bars of stainless steel.

\section{Discussion and Conclusions}

From the analysis of the different cases presented in this paper, a number of conclusions can be extracted, which follow.

- The cases where thermal insulation is positioned outside the enclosure and completely surrounds the building (Cases 3, 6 and 7) show that the outgoing flow is much lower than the cases where the insulation is placed on the inside or outside, but where the slab is not covered. The flow value that these cases reach lies in the vicinity of $60 \%$ of loss in the rest of cases. A saving of around 14 watts per linear meter of façade is reached. It is equivalent to the loss that would occur in the order of $0.2 \mathrm{~m}^{2}$ of glazing.

- With the study of the façade-slab connection, we see in cases 1, 2, 4 and 5 that the thermal insulation situation practically has not influence, inside or outside, since in these cases are not lining the front of the slab.

- The new constructive detail which interrupts the cantilever with a prefabricated part, so that the insulation is continuous from top to bottom, is equivalent to the traditional solution of wrapping the cantilever with insulation (Fig. 6 and 7).

- The case of uninhabited and unheated flats produces condensation on the ceiling of the inferior house inhabited in the encounter with the facade, due to thermal bridge forming the slab. In case of cantilever, this situation is aggravated because the surface of the cantilever acts as a heat sink.

This work will be expanded in the future with field work, taking measurements of temperature and moisture on site and with the comparison the temperature values of the façade with the data obtained by infrared thermography (following [5]).

\section{References}

[1] He, J., Hoyano, A., Asawa, T. A numerical simulation tool for predicting the impact of outdoor thermal environment on building energy performance. Applied Energy 86 (2009) 1596-1605. DOI: 10.1016/j.apenergy.2008.12.034.

[2] Füllsack-Köditz, R. Bauphysikalische Kennwerte für Balkonplattenanschlüsse. Bauphysik 34 (2012), Heft 3, p. 121-129. DOI: 10.1002/bapi.201200015.

[3] Sami A. Al-Sanea, M.F. Zedan. Effect of thermal bridges on transmission loads and thermal resistance of building walls under dynamic conditions. Applied Energy 98 (2012) 584-593. DOI: 10.1016/j.apenergy.2012.04.038.

[4] ZT Ai, CM Mak, JL Niu, ZR Li. Effect of balconies on thermal comfort in wind-induced, naturally ventilated low-rise buildings. Building Serv. Eng. Res. Technol. 32,3 (2011) pp. 277-292. DOI: $10.1177 / 0143624410396431$.

[5] Lerma, C., Mas, Á., Gil, E., Vercher, J., Peñalver, MJ. Identification of construction material pathologies in historical buildings using infrared thermography. Materiales de Construcción (2013) pp. 24-34. DOI: 10.3989/mc.2013.06612. 